\title{
Combining Structural Brain Changes Improves the Prediction of Alzheimer's Disease and Mild Cognitive Impairment
}

\author{
Ningnannan Zhang ${ }^{a, c} \quad$ Xiaowei Song ${ }^{a, b} \quad$ Yunting Zhang ${ }^{c}$ for the Alzheimer's \\ Disease Neuroimaging Initiative \\ aNational Research Council Canada Institute for Biodiagnostics (Atlantic), and bivision of Geriatric Medicine, \\ Department of Medicine, Dalhousie University, Halifax, N.S., Canada; 'Department of Radiology of the General \\ Hospital, Tianjin Medical University, Tianjin, China
}

\section{Key Words}

Aging $\cdot$ Alzheimer's disease $\cdot$ Brain atrophy and lesion index $\cdot$ Mild cognitive impairment $\cdot$ Medial temporal lobe atrophy scale $\cdot$ Structural magnetic resonance imaging

\begin{abstract}
Background: Several structural brain changes have been associated with Alzheimer's disease (AD). This study investigated the prediction of $A D$ by combining multiple brain changes with the hallmark medial temporal lobe atrophy (MTA). Methods: High-resolution magnetic resonance imaging (MRI) data of people with mild AD ( $n=39)$, mild cognitive impairment $(\mathrm{MCl} ; \mathrm{n}=82)$, and of healthy controls $(\mathrm{HC}$; $\mathrm{n}=58$ ) were obtained at baseline. Among these people, 26 $\mathrm{AD}, 53 \mathrm{MCl}$, and $46 \mathrm{HC}$ subjects had 24-month follow-up MRI scans. Bilateral MTA was evaluated using a medial temporal lobe atrophy scale (MTAS). Common changes in the aging brain were summarized using a brain atrophy and lesion index (BALI). The performance of the MTAS, BALI, and a score combining both, using a logistic regression model, were assessed. Results: The MTAS and BALI scores were closely correlated $\left(r^{2}>0.56\right)$; each differed between the diagnostic groups. Having an unfavorable MTAS score was associated with an increased risk of $\mathrm{MCl}-\mathrm{AD}$ conversion $(\mathrm{OR}=3.71, \mathrm{p}$ $=0.039$ ), adjusted for age, sex, and education; having an
\end{abstract}

unfavorable BALI score marginally contributed to such risks $(\mathrm{OR}=4.08, \mathrm{p}=0.080)$. Combining MTAS and BALI components resulted in a greater OR $(8.99, \mathrm{p}=0.007)$ and an improved predictive accuracy $(75.9 \%, p=0.002)$. Conclusion: Multiple structural changes have an additive effect on AD. The data support potential future roles of combining multiple coexisting structural changes to benefit AD diagnosis, progression monitoring, and/or treatment effect evaluation.

Copyright $\odot 2012$ S. Karger AG, Basel

\section{Introduction}

Alzheimer's disease (AD) is a progressive neurodegenerative disorder characterized by brain damage pri-

Data used in preparation of this article were obtained from the Alzheimer's Disease Neuroimaging Initiative (ADNI) database (www.loni.ucla.edu/ADNI). As such, the investigators within the ADNI contributed to the design and implementation of ADNI and/ or provided data but did not participate in analysis or writing of this report. ADNI is the result of efforts of many coinvestigators from a broad range of academic institutions and private corporations. The Principal Investigator is Michael W. Weiner, MD, VA Medical Center and University of California - San Francisco. A complete listing of ADNI investigators is available at http://www.loni.ucla.edu/ADNI/ Collaboration/ADNI_Manuscript_Citations.pdf.

\section{KARGER}

Fax +41613061234

E-Mail karger@karger.ch

www.karger.com (c) 2012 S. Karger AG, Basel

$1420-8008 / 12 / 0335-0318 \$ 38.00 / 0$

Accessible online at:

www.karger.com/dem
Xiaowei Song, $\mathrm{PhD}$, MSCS

Neuroimaging Research Laboratory

National Research Council Canada, Institute for Biodiagnostics (Atlantic)

Suite 3900, 1796 Summer Street

Halifax, NS B3H $3 \mathrm{~A} 7$ (Canada)

Tel. +1 9024731 876, E-Mail Xiaowei.Song@nrc.ca 
marily in the medial temporal lobe (i.e., the entorhinal cortex, hippocampus, and the adjacent peri/para-hippocampal cortices) - the key structure for declarative memory. Magnetic resonance imaging (MRI) evaluation of medial temporal lobe atrophy (MTA) has been sensitively related to $\mathrm{AD}$ expression and been proposed as a neuroimaging biomarker to aid in $\mathrm{AD}$ diagnosis and differentiation [1-3]. Characteristic MTA has also been proven valuable in predicting dementia and $\mathrm{AD}$ progression $[4,5]$. In recent years, a number of additional structural changes commonly present in the aging brain (e.g. global gray matter atrophy, subcortical infarcts, white matter lesions, and cerebrovascular diseases) have also been found to increase the risks of cognitive impairment and dementia [6-12]. Importantly, many such changes coexist; each can be associated with MTA worsening and affect cognition [13-20]. Consequently, the importance of evaluating the combined effect of multiple brain deficits on cognitive decline is increasingly recognized [16-18].

To facilitate the evaluation of the combined effect of global brain changes on cognition, a high-field MRIbased semi-quantitative brain atrophy and lesion index (BALI) has been developed [21, 22]. The BALI adapts several standardized visual rating scales to capture a range of structural deficits in the supratentorial and infratentorial regions and summarizes these brain changes with a total score. BALI rating is feasible to perform and has been shown to be useful to describe the variability of the brain in people with $\mathrm{AD}$, mild cognitive impairment (MCI) and in healthy control (HC) older adults, as well as to correlate brain structural and functional changes [21, 22 ]. However, it is yet to be understood whether multiple structural deficits other than MTA, as combined in BALI, can contribute to $\mathrm{AD}$ and $\mathrm{MCI}$ discrimination and prediction. The objectives of the present study were to investigate (1) the correlation between BALI and MTA and (2) the value of combining multiple brain changes in the prediction of $\mathrm{AD}$ and MCI. To accomplish these objectives, we carried out a secondary analysis using the highfield (i.e., 3 T) high-resolution MRI from the Alzheimer's Disease Neuroimaging Initiative (ADNI). An MTA rating scale (MTAS) and a BALI score were assigned to each subject. We assessed the performance of BALI, MTAS, and a combination of both (i.e., BALI-MTAS) in discriminating $\mathrm{MCI}$ and mild $\mathrm{AD}$ and in predicting $\mathrm{MCI}$ to $\mathrm{AD}$ conversion.

\section{Methods}

Subjects and Clinical Assessments

Data used for the present analysis were obtained from the ADNI with permission [23]. The ADNI was launched in 2003 by the National Institute on Aging, the National Institute of Biomedical Imaging and Bioengineering, the Food and Drug Administration, private pharmaceutical companies and nonprofit organizations, as a USD 60-million, 5-year public-private partnership. The primary goal of ADNI has been to test the use of serial MRI, positron emission tomography, and other biological markers in the progression of MCI and early AD. Determination of sensitive and specific markers of very early $\mathrm{AD}$ progression is intended to aid researchers and clinicians to develop new treatments and monitor their effectiveness, as well as lessen the time and cost of clinical trials. Subjects have been recruited from over 50 sites across the USA and Canada, with the initial goal to recruit 800 adults, ages 55-90 (200 cognitively normal older individuals to be followed for 3 years, 400 people with MCI to be followed for 3 years, and 200 people with early AD to be followed for 2 years) [23].

Diagnostic categorization and classification of conversion between diagnostic groups were made by ADNI site physicians in accordance with the criteria of the National Institute of Neurologic and Communicative Disorders and Stroke/ Alzheimer's Disease and Related Disorders Association (NINCDS/ADRDA) and were reviewed by ADNI clinical monitors. Analyses involving diagnostic categorization at follow-up have taken into account information about disease conversion. Clinical testing scores on global cognition were downloaded from the ADNI clinical dataset. These scores included the Mini-Mental State Examination, the Alzheimer's Disease Assessment Scale-cognitive subscale, and the Clinical Dementia Rating Scale.

For this analysis, all the accessible imaging data of the subjects who had 3-tesla MRI were downloaded $(\mathrm{AD}=39$; $\mathrm{MCI}$ $=82 ; \mathrm{HC}=58$; from 30 ADNI sites). At the 24-month followup, $13 \mathrm{AD}, 29 \mathrm{MCI}$, and $12 \mathrm{HC}$ did not have a scan. Highresolution (1.2 $\mathrm{mm}$ thickness) 3D images (MP-RAGE) were evaluated [24]. Before they were made available in the ADNI database for public access, all MRI scans had been checked by ADNI researchers for quality control purposes so that any image with unsatisfactory quality had been excluded from the downloadable data. All images obtained from the ADNI website satisfied the requirements of the present study; therefore, no further selection criteria were imposed for further image selection after they were downloaded.

\section{Evaluation of Structural Changes}

Evaluation of the imaging data was performed independently by two neuroradiologists trained with the rating methods (as described in online suppl. Appendix 1; for all online suppl. material, see www.karger.com/doi/10.1159/000339364). Brain images were rated in a random order, while the raters were blinded to the subjects' demographic, diagnosis, cognitive information, and to the time of scan. Examples for MTAS and BALI evaluations are shown in figure 1. 


\begin{tabular}{ll}
\hline & $(a \mathrm{HC}$ subject) \\
Medial temporal lobe \\
atrophy
\end{tabular}

Fig. 1. Example images showing the rating of the MTAS and the BALI. a A HC (76 years old, male). b A subject diagnosed with $\mathrm{AD}$ (83 years old, female). Locations of specific deficits under evaluation are indicated by white arrows.

MTAS Evaluation. A standardized MTA rating scale was used to assess each side of the bilateral MTA in the coronal plane, applying the approach described by Scheltens et al. [25]. Specifically, the left and the right sides of the medial temporal lobe were assessed independently according to a grading schema of $0-4$ that rates the width of the choroidal fissure, the width of the temporal horn, and the height of the hippocampus. A total MTAS score was assigned to each subject as the sum of both sides' scores, with a possible maximum value of 8 , where a higher score meant greater MTA (online suppl. Appendix 1, panel A).

BALI Evaluation. Seven categories of structural changes commonly present in the aging brain were evaluated by adapting existing rating scales for the construction of the BALI [21,
22]. These changes included deficits in the infratentorial, deep white matter, periventricular, basal ganglia, gray matter, small vessels, global atrophy, and other aspects if applicable (e.g. neoplasm, trauma, and deformation). Specifically, ratings of each category were performed in the axial plane on the images applying the rating schema to generate category subscores. A total BALI rating score was assigned to each subject as the sum of the subscores, with a possible maximum value of 25 , with a higher score representing a greater level of global brain structural deficits (online suppl. Appendix 1, panel B).

Combined BALI-MTAS. To combine MTAS and BALI, a logistic regression (LR) model that allows the discrimination between affected and unaffected individuals was employed. Here, being affected meant converting from MCI to AD during the 2-year follow-up period. The MTAS and the BALI components were included in the LR as covariates, so that their relative risks for MCI conversion (vs. MCI stable), analogous to the regression coefficients, were estimated. The combined BALIMTAS score was calculated as the sum of the input scores (i.e., the covariates) in accordance with their relative risk estimated using the LR model, as described by the following: $f(z)=1$ / $\left(1+e^{-z}\right) ; z=\beta_{0}+\beta_{1} x_{1}+\beta_{2} x_{2}+\ldots+\beta_{k} x_{k}$; where $f(z)$ represents the combined BALI-MTAS score ranging between a possible minimum of 0 and maximum of $1, x_{1}, x_{2}, \ldots x_{k}$ represent MTAS and BALI items, $\beta_{0}$ represents the intercept, and $\beta_{1}$, $\beta_{2} \ldots \beta_{k}$ represent the respective regression coefficients associated with each item.

\section{Statistical Analyses}

Analyses were performed using 179 subjects at baseline and using 125 subjects who had follow-up scans. Reliability of the ratings was examined using the intraclass correlation coefficient (ICC) and the interrater agreement rate (Cohen's kappa) on a subsample of $20 \%$ of randomly selected subjects. The mean value was used in the analyses in case of disagreement between the two raters. Group differences regarding demographics, clinical assessments, and the brain structural rating scores were examined using Kruskal-Wallis nonparametric tests for interval data and $\chi^{2}$ tests for categorical/ordinal data. Odds ratios (ORs) and the $95 \%$ confidence intervals (CIs) of the MTAS, BALI, and BALI-MTAS in discriminating AD and MCI versus $H C$ and in predicting MCI subjects who converted to $\mathrm{AD}$ over 2 years versus those who remained MCI were assessed using univariate LR and using multivariate LR, adjusted for age, sex, and education level. Correlations between MTAS and BALI and their relationships with global cognitive testing scores were examined using correlation and regression analyses. Receiver operating characteristic analysis (ROC) was used to examine the performance of MTAS, BALI, and BALI-MTAS in predicting the 2 -year conversion from $\mathrm{MCI}$ to $\mathrm{AD}$, assessed using the areas under the ROC curve (AUC). Sensitivity analysis was performed; dichotomization of the scores was made using optimal cut-off points at which a further increase of sensitivity resulted in a minimal decrease of specificity. The cutoff points were: MTAS $\leq 3$ vs. $>3$ (of 8 , the possible maximum value), $\mathrm{BALI} \leq 11$ vs. $>11$ (of 25 ), and BALI-MTA $\leq 0.6$ vs. $>0.6$ (of 1). 
Table 1. Demographics of the study sample

\begin{tabular}{|c|c|c|c|c|c|c|c|}
\hline Group & Alzheimer's disease & MCI, all & Healthy control & $\mathrm{p}$ & MCI, converter & MCI, stable & $\mathrm{p}$ \\
\hline Sample size baseline & 39 & 82 & 58 & - & - & - & - \\
\hline Sample size follow-up & 26 & 53 & 46 & - & 31 & 22 & - \\
\hline Female, $\%$ & 59.0 & 34.1 & 62.1 & 0.002 & 29.0 & 40.9 & 0.368 \\
\hline Education, years & $14.7 \pm 2.4$ & $15.4 \pm 2.9$ & $15.4 \pm 2.7$ & 0.844 & $15.7 \pm 2.7$ & $14.9 \pm 2.8$ & 0.344 \\
\hline MMSE (/30) & $23.0 \pm 2.1$ & $26.6 \pm 2.9$ & $29.3 \pm 0.9$ & $<0.001$ & $26.4 \pm 1.8$ & $27.6 \pm 2.0$ & 0.014 \\
\hline MTAS (/8) baseline & $3.9 \pm 2.0$ & $3.4 \pm 1.8(4)$ & $2.4 \pm 1.2(2)$ & $<0.001$ & $3.5 \pm 1.9(3)$ & $2.3 \pm 1.6(2)$ & 0.015 \\
\hline MTAS (/8) follow-up & $4.9 \pm 2.3(4)$ & $3.7 \pm 2.0(4)$ & $2.6 \pm 1.2(2)$ & $<0.001$ & $4.3 \pm 2.1(4)$ & $2.7 \pm 1.5$ & 0.006 \\
\hline BALI (/25) baseline & $11.2 \pm 3.1$ & $10.4 \pm 2.7$ & $9.9 \pm 2.4$ & 0.072 & $10.7 \pm 2.8$ & $9.5 \pm 2.6$ & 0.118 \\
\hline BALI (/25) follow-up & $12.4 \pm 2.7$ & $11.0 \pm 2.3$ & $11.0 \pm 2.4$ & 0.001 & $12.0 \pm 2.7$ & $9.9 \pm 2.1$ & 0.006 \\
\hline
\end{tabular}

Data are presented as means \pm standard deviations, otherwise as indicated. ADAS-cog $=$ Alzheimer's Disease Assessment Scalecognitive subscale; $\mathrm{CDR}=$ clinical dementia rating. $\mathrm{p}$ value $=$ Significance for the comparisons between $\mathrm{AD}, \mathrm{MCI}, \mathrm{HC}$ and between $\mathrm{MCI}$ subjects who converted to $\mathrm{AD}$ and those who maintained with MCI.

${ }^{1}$ Median values are presented in brackets.

All analyses were performed using SPSS ${ }^{\odot} 17.0$ software package and codes developed using Matlab ${ }^{\odot}$ R2007. Significance level was set at $\mathrm{p}<0.05$ with two-tailed tests.

\section{Results}

There was no baseline difference in the mean age, education level, or sex ratio between the $\mathrm{AD}$ and $\mathrm{HC}$ groups (table 1). As expected, subjects with AD showed worse cognitive testing scores and greater levels of structural brain changes in terms of both MTAS and BALI ( $\mathrm{p} \leq 0.001)$. The MCI-AD converters did not statistically differ from the nonconverters regarding age, sex, or education (table 1), but they showed comparatively poorer cognitive performance $(\mathrm{p}<0.010)$. The converters also had worse MTAS and BALI scores, especially at the follow-up scans $(\mathrm{p}=0.006)$.

Good ICC values and moderate kappa values were obtained for both MTAS $(\mathrm{ICC}=0.88,95 \% \mathrm{CI}=0.79-0.94$; kappa $=0.66,95 \% \mathrm{CI}=0.46-0.76)$ and BALI $(\mathrm{ICC}=0.91$, $95 \% \mathrm{CI}=0.84-0.96$; $\mathrm{kappa}=0.50,95 \% \mathrm{CI}=0.35-0.66)$, demonstrating acceptable reliability of these measures. The MTAS and BALI scores were highly correlated $\left(\mathrm{r}^{2}>\right.$ $0.56, \mathrm{p}<0.001$; fig. 2 ); but they varied considerably in a few individuals, suggesting a certain level of independency. MTAS and BALI each correlated significantly with the global cognition scores $\left(\mathrm{r}^{2}=0.13-0.30, \mathrm{p}<0.001\right.$ for MTAS; $\mathrm{r}^{2}>0.04, \mathrm{p}<0.050$ for BALI).

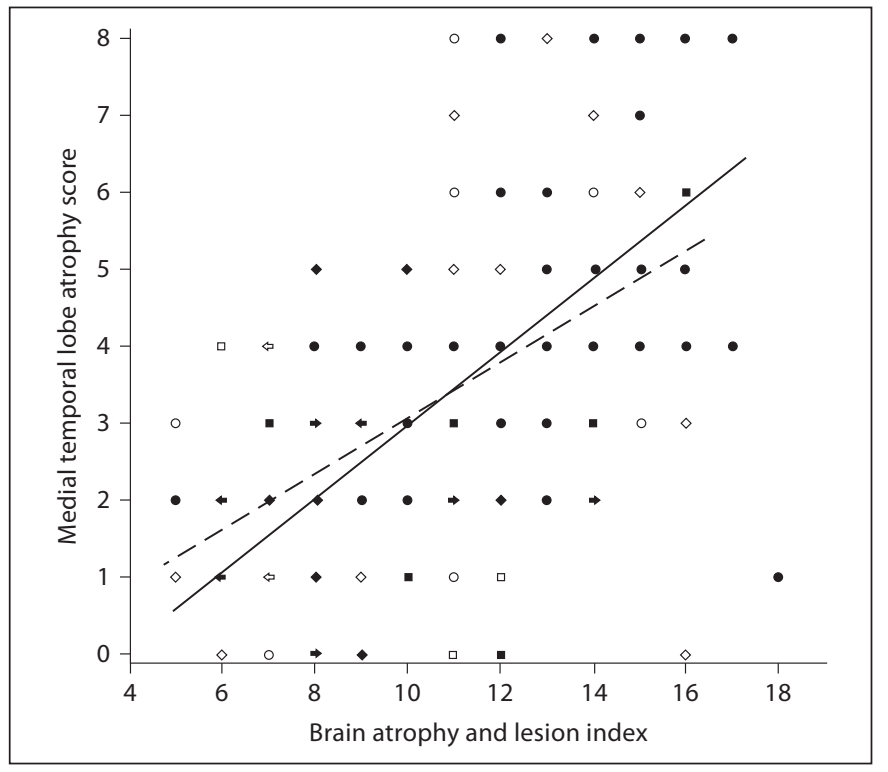

Fig. 2. Relationships between the BALI and the MTAS. Symbols represent the observational data (circles: AD; diamond: $\mathrm{MCI}$; squares: $\mathrm{HC}$ ) and lines describe the linear fitting (MTAS $=\mathrm{a}+\mathrm{b}$ - BALI). At baseline: $\mathrm{a}=-0.542, \mathrm{~b}=0.361, \mathrm{n}=179, \mathrm{r}^{2}=0.555, \mathrm{p}$ $<0.001$; open symbols; dashed line. At follow-up: $\mathrm{a}=-1.865, \mathrm{~b}=$ $0.480, \mathrm{n}=125, \mathrm{r}^{2}=0.565, \mathrm{p}<0.001$; filled symbols; solid line.

An increase in the MTAS score was associated with an increased risk of $\mathrm{AD}(\mathrm{OR}=1.80$ at baseline, $\mathrm{OR}=2.01$ at follow-up, 95\% CI = 1.32-2.81) and of baseline MCI (OR 
Table 2. Prediction of the risk for 2-year AD conversion from MCI $(n=53)$ using the MTAS, BALI, and the combined BALIMTAS scores in a multivariate logistic regression model adjusted for age (years), sex, and education

\begin{tabular}{|c|c|c|c|c|c|c|}
\hline \multirow{5}{*}{$\begin{array}{l}\text { Model } \\
1\end{array}$} & \multirow{2}{*}{$\begin{array}{l}\text { Covariate } \\
\text { age }\end{array}$} & \multirow{2}{*}{$\begin{array}{l}\text { Odds } \\
\text { ratio }\end{array}$} & \multicolumn{2}{|c|}{$\begin{array}{l}95 \% \\
\text { Confidence } \\
\text { interval }\end{array}$} & \multirow{2}{*}{$\begin{array}{l}\text { Wald's } \\
0.06\end{array}$} & \multirow{2}{*}{$\begin{array}{l}\mathrm{p} \\
0.807\end{array}$} \\
\hline & & & 0.91 & 1.08 & & \\
\hline & sex & 1.21 & 0.31 & 4.64 & 0.07 & 0.785 \\
\hline & education & 1.10 & 0.88 & 1.38 & 0.75 & 0.385 \\
\hline & MTAS & 3.71 & 1.07 & 12.91 & 4.24 & 0.039 \\
\hline \multirow[t]{4}{*}{2} & age & 0.97 & 0.89 & 1.06 & 0.48 & 0.491 \\
\hline & sex & 0.76 & 0.20 & 2.87 & 0.17 & 0.683 \\
\hline & education & 1.03 & 0.81 & 1.30 & 0.05 & 0.833 \\
\hline & BALI & 4.08 & 0.85 & 19.68 & 3.07 & 0.080 \\
\hline \multirow[t]{4}{*}{3} & age & 0.94 & 0.85 & 1.04 & 1.65 & 0.200 \\
\hline & sex & 1.21 & 0.29 & 4.92 & 0.07 & 0.791 \\
\hline & education & 1.04 & 0.82 & 1.32 & 0.10 & 0.748 \\
\hline & BALI-MTAS & 8.99 & 1.81 & 44.65 & 7.21 & 0.007 \\
\hline
\end{tabular}

$=1.36,95 \% \mathrm{CI}=1.00-1.80)$. An increase in the BALI was also associated with an increased risk of $\mathrm{AD}(\mathrm{OR}=1.19$ at baseline, $\mathrm{OR}=1.22$ at follow-up, $95 \% \mathrm{CI}=1.02-1.44)$, although not with MCI $(\mathrm{p}>0.05)$. Using the combined BALI-MTAS score, the OR for AD increased to 1.94 at baseline and 2.15 at follow-up $(95 \% \mathrm{CI}=1.41-2.87)$; the OR for MCI increased to 1.69 at baseline and 1.75 at follow-up $(95 \% \mathrm{CI}=1.30-2.63)$.

In a multivariable model adjusted for age, sex, and education, the 2-year conversion from $\mathrm{MCI}$ to $\mathrm{AD}$ was significantly associated with MTAS $(\mathrm{OR}=3.71, \mathrm{p}=0.039$; table 2), and somewhat with BALI (OR $=4.08, \mathrm{p}<0.080$; table 2). This was in contrast to the typical insignificant association when the predictive validity of each individual BALI component (but save global atrophy) was assessed ( $\mathrm{p}>0.05$; online suppl. Appendix 2). Compared to either BALI or MTAS, the combined BALI-MTAS was associated with a greater risk for MCI-AD conversion $(\mathrm{OR}=8.99$, $\mathrm{p}<0.007$; table 2). Improved performance for discriminating individuals who had $\mathrm{AD}(\mathrm{AUC}=82.4 \%, \mathrm{p}<0.001)$ and $\mathrm{MCI}(\mathrm{AUC}=67.0 \%, \mathrm{p}=0.004)$, and for predicting individuals who converted from MCI to AD (AUC $=75.9 \%$, $\mathrm{p}=0.002$ ), was also observed (fig. 3; table 3).

\section{Discussion}

We investigated the effect of combining MTA and several other common changes including global atro-

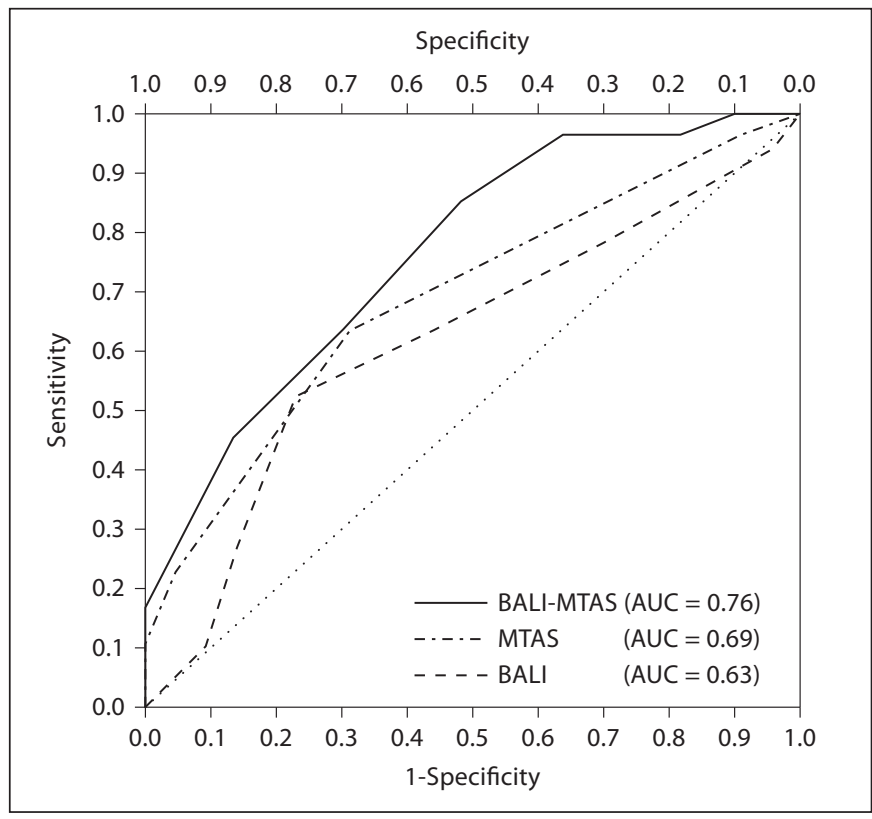

Fig. 3. ROC analysis for the 2-year prediction of individuals with MCI ( $\mathrm{n}=53$ ) who converted to AD versus those who remained with MCI. Dashed line: BALI; dot-dashed line: MTAS; solid line: combined BALI-MTAS. Diagonal lines indicate accuracy $=0.50$.

Table 3. Sensitivity (Sen), specificity (Spe), and AUC for the MTAS, BALI, and the combined BALI-MTAS scores in discriminating $\mathrm{AD}$ and $\mathrm{MCI}$ and in predicting $\mathrm{MCI}-\mathrm{AD}$ conversion

\begin{tabular}{llllll}
\hline Group & Score & Sen & Spe & AUC & p \\
\hline AD vs. HC & MTAS & 0.73 & 0.72 & 0.737 & 0.001 \\
$(\mathrm{n}=97)$ & BALI & 0.65 & 0.70 & 0.702 & 0.003 \\
& BALI-MTAS & 0.73 & 0.74 & 0.824 & $<0.001$ \\
\hline MCI vs. HC & MTAS & 0.51 & 0.72 & 0.604 & 0.076 \\
$(\mathrm{n}=140)$ & BALI & 0.53 & 0.41 & 0.485 & 0.803 \\
& BALI-MTAS & 0.51 & 0.76 & 0.670 & 0.004 \\
\hline AD vs. MCI & MTAS & 0.50 & 0.60 & 0.605 & 0.130 \\
$(\mathrm{n}=121)$ & BALI & 0.69 & 0.60 & 0.627 & 0.068 \\
& BALI-MTAS & 0.62 & 0.60 & 0.640 & 0.045 \\
\hline MCI-AD & MTAS & 0.65 & 0.68 & 0.692 & 0.018 \\
conversion vs. & BALI & 0.61 & 0.59 & 0.625 & 0.125 \\
stable ( $=53)$ & BALI-MTAS & 0.74 & 0.68 & 0.759 & 0.002 \\
\hline
\end{tabular}

phy, white matter lesions, and cerebrovascular changes in the prediction of $\mathrm{AD}$. We compared the performance of the combined score with that of either the MTA measure (i.e., MTAS) or the global measure of brain struc- 
ture (i.e., BALI). While the data confirmed that MTA was the most dominating brain deficit for $\mathrm{AD}$, they also strongly suggested that other brain changes had an additive effect. In addition, the result demonstrated that combining various coexisting structural changes helped improve the discrimination of $\mathrm{AD}$ and $\mathrm{MCI}$, and the prediction of short-term (here, 24 months) MCI-AD conversion.

MRI-based MTAS is a recognized clinical neuroimaging biomarker for AD $[1-5,26,27]$. The featured MTA has been used to predict $\mathrm{AD}$ with performance ranging from 60 to $81 \%$, depending on study settings, disease severity, follow-up durations, measurement methods, and statistical approaches $[4,5,28-30]$. AD prediction with a higher accuracy may be achieved, although typically in well-established disease and when neuropsychological and clinical assessments are also taken into consideration, which can be over a decade behind the detectable structural MRI changes [31]. In general, volumetric measures and visual rating have each been used evaluating neuroimaging, particular MRI, although inter-study variations can occur using either technique [32-35]. Consistent with previous studies, our data showed a medium-high predictive value with the use of MTAS [4, $28,36]$.

An apparent difficulty with solely MTA-based clinical AD diagnosis is the comparatively unsatisfactory specificity that may not be superior to the level based on detailed clinical assessments, whereas people with $\mathrm{AD}$ may not just show MTA in the brain. In recent years, multiple other structural deficits, especially those affected by vascular risk factors, have been shown to present in $\mathrm{AD}$ with greater severity and prevalence. As a result, additional structural brain changes have been proven informative; some of them have been proposed as novel AD MRI biomarkers [6, 8,10, 15, 37-39]. Importantly, more studies have shown that multiple structural brain deficits may not present in isolation. They often coexist $[13-15,19]$. Further, these changes can affect MTA interactively and can have an impact on cognition collectively [14, 40-44].

Prediction of $\mathrm{AD}$ and cognitive decline using multiple structural MRI-defined deficits has emerged as a promising topic in $\mathrm{AD}$ research. Including additional structural changes to achieve more accurate discriminative and diagnostic performance of MTA has been demonstrated [6, 45-47]. In these studies, improved predictive specificity, sensitivity, and/or accuracy have been achieved by combining MTA with regional or global white matter changes $[6,45]$, with cerebral atrophy in parietal and prefrontal regions [46], or with cerebral atrophy and white matter lesions [47]. As a global measure of brain aging, the BALI facilitates such multivariable approaches, by not just considering a specific deficit of choice, but considering various common changes that coexist in the brain. As shown by the data, several seemingly subtle structural changes, when each showed only an inclination of contribution to $\mathrm{AD}$ and $\mathrm{MCI}$, revealed a significant effect when considered collectively using a summarizing index (i.e., BALI); combining them with MTA greatly improved the predictive validity of MTA. Here, an additive effect of multiple brain changes on $\mathrm{AD}$ is seen. The study supports the potential future role of combining multiple structural changes to help improve $\mathrm{AD}$ diagnosis, progression monitoring, and/or treatment evaluation, which should also shed light on controlling $\mathrm{AD}$ risk factors, including modifiable vascular risk factors that are associated with these brain changes [48].

Our data must be interrelated with caution. First, we used visual scales, which in general are relatively crude compared to some more precise quantifications that usually involve a great deal of expert input and tiresome processing. On the other hand, the good ICC and the moderate kappa are in favor of them as reliable measures that are useful in both clinical and research settings [49, 50]. To test the agreement of visual scale and volumetric estimation, we also obtained the voxel-based morphometry of MTA for a subset of the sample from the ADNI clinical dataset; the correlation coefficient between the two was significant $\left(r^{2}=0.43, p<0.001\right)$. In addition, the BALI rating has been validated using high-resolution, high-field MRI (i.e., $3 \mathrm{~T}$ that has become the mainstream of clinical MRI); we only included subjects with 3-tesla scans in the analysis; the greater tissue contrasts have allowed reliable rating $[21,22]$. Whether this finding can be generalized using low-moderate MRI systems (e.g. $1.5 \mathrm{~T}$ or lower) is not yet evident. Another limitation concerns the way of component weighting. We chose to use the LR model to obtain the relative risks of the input categories to combine MTAS and BALI. This was chiefly because such an approach is widely available and commonly applied. Certainly, other processing methods may also be applicable to carry out the task, although it has been shown that differences in the predictive performance are chiefly determined by the nature of data [51]. How to better coordinate the relative contributions of MTA and multiple other relevant brain deficits to improve $\mathrm{AD}$ diagnosis deserves further investigation. In the future, larger-scale MRI studies with a long follow-up time would be particularly beneficial. 


\section{Acknowledgements}

This research was supported by the Nova Scotia Research Foundation (NSHRF-MED2086), Capital Health Research Foundation (CDHA-RO33), National Basic Research Program of China (973 Program, No. 2010CB732500), and the National Natural Science Foundation of China (Major Program, No. 30730036). N.Z. receives a National Research Council Canada fellowship from the Chinese Ministry of Education and a research grant from the Postgraduate Foundation of Tianjin Medical University (No. 2009GSI13) as a joint PhD candidate. We acknowledge Dr. Wei Chen for help with evaluating brain images, and Stephanie Smith and Emily LeBlanc for proofreading the manuscript.

Data collection and sharing for this project was funded by the Alzheimer's Disease Neuroimaging Initiative (ADNI) (National Institutes of Health Grant U01 AG024904). ADNI is funded by the National Institute on Aging, the National Institute of Biomedical Imaging and Bioengineering, and through gen- erous contributions from the following: Abbott, AstraZeneca $A B$, Bayer Schering Pharma AG, Bristol-Myers Squibb, Eisai Global Clinical Development, Elan Corporation, Genentech, GE Healthcare, GlaxoSmithKline, Innogenetics, Johnson and Johnson, Eli Lilly and Co., Medpace, Inc., Merck and Co., Inc., Novartis AG, Pfizer Inc., F. Hoffman-La Roche, ScheringPlough, Synarc, Inc., and Wyeth, as well as non-profit partners the Alzheimer's Association and Alzheimer's Drug Discovery Foundation, with participation from the US Food and Drug Administration. Private sector contributions to ADNI are facilitated by the Foundation for the National Institutes of Health (www.fnih.org). The grantee organization is the Northern California Institute for Research and Education, and the study is coordinated by the Alzheimer's Disease Cooperative Study at the University of California, San Diego. ADNI data are disseminated by the Laboratory for Neuro Imaging at the University of California, Los Angeles. This research was also supported by NIH grants P30 AG010129, K01 AG030514, and the Dana Foundation.

\section{References}

1 Duara R, Loewenstein DA, Potter E, Appel J, Greig MT, Urs R, Shen Q, Raj A, Small B, Barker W, Schofield E, Wu Y, Potter H: Medial temporal lobe atrophy on MRI scans and the diagnosis of Alzheimer disease. Neurology 2008;71:1986-1992.

-2 Dubois B, Feldman HH, Jacova C, Dekosky ST, Barberger-Gateau P, Cummings J, Delacourte A, Galasko D, Gauthier S, Jicha G, Meguro K, O’brien J, Pasquier F, Robert P, Rossor M, Salloway S, Stern Y, Visser PJ, Scheltens P: Research criteria for the diagnosis of Alzheimer's disease: revising the NINCDS-ADRDA criteria. Lancet Neurol 2007;6:734-746.

-3 Galluzzi S, Talassi E, Belussi M, Scheltens P, van de Pol L, Nobili F, Rodriguez G, Froelich L, Damian M, Martinez-Lage P, Gomez-Isla T, Reynish E, Ousset PJ, Vellas B, Frisoni GB: Multi-center comparison of medial temporal atrophy in patients with Alzheimer's disease - Data from the ICTUS study. Dement Geriatr Cogn Disord 2008;26:314-322.

-4 Korf ES, Wahlund LO, Visser PJ, Scheltens P. Medial temporal lobe atrophy on MRI predicts dementia in patients with mild cognitive impairment. Neurology 2004;63:94-100.

$\checkmark 5$ Geroldi C, Rossi R, Calvagna C, Testa C, Bresciani L, Binetti G, Zanetti O, Frosoni GB: Medial temporal atrophy but not memory deficit predicts progression to dementia in patients with mild cognitive impairment. J Neurol Neurosurg Psychiatry 2006;77: 1219-1222.

-6 Prasad K, Wiryasaputra L, Ng A, Kandiah N: White matter disease independently predicts progression from mild cognitive impairment to Alzheimer's disease in a clinic cohort. Dement Geriatr Cogn Disord 2011;31:431-434.
7 Vernooij MW, Ikram MA, Tanghe HL, Vincent AJ, Hofman A, Krestin GP, Niessen WJ, Breteler MM, van der Lugt A: Incidental findings on brain MRI in the general population. N Engl J Med 2007;357:1821-1828.

-8 Schneider JA, Boyle PA, Arvanitakis Z, Bienias JL, Bennett DA: Subcortical infarcts, Alzheimer's disease pathology, and memory function in older persons. Ann Neurol 2007; 62:59-66.

-9 Prins ND, van Dijk EJ, den Heijer T, Vermeer SE, Koudstaal PJ, Oudkerk M, Hofman A, Breteler MM: Cerebral white matter lesions and the risk of dementia. Arch Neurol 2004;61:1531-1534.

10 Sinka L, Kövari E, Gold G, HofPR, Herrmann FR, Bouras C, Giannakopoulos P: Small vascular and Alzheimer disease-related pathologic determinants of dementia in the oldest-old. J Neuropathol Exp Neurol 2010; 69:1247-1255.

11 Silbert LC, Howieson DB, Dodge H, Kaye JA: Cognitive impairment risk: white matter hyperintensity progression matters. Neurology 2009;73:120-125.

12 Stenset V, Hofoss D, Berstad AE, Negaard A, Gjerstad L, Fladby T: White matter lesion subtypes and cognitive deficits in patients with memory impairment. Dement Geriatr Cogn Disord 2008;26:424-431.

13 Agosta F, Pievani M, Sala S, Geroldi C, Galluzzi S, Frisoni GB, Filippi M: White matter damage in Alzheimer disease and its relationship to gray matter atrophy. Radiology 2011; 258:853-863.
14 Eckerström C, Olsson E, Klasson N, Bjerke M, Göthlin M, Jonsson M, Rolstad S, Malmgren H, Wallin A, Edman A: High white matter lesion load is associated with hippocampal atrophy in mild cognitive impairment. Dement Geriatr Cogn Disord 2011; 31:132-138.

15 de Leeuw FE, Korf E, Barkhof F, Scheltens P: White matter lesions are associated with progression of medial temporal lobe atrophy in Alzheimer disease. Stroke 2006;37: 2248-2252.

-16 Raji CA, Lopez OL, Kuller LH, Carmichael OT, Longstreth WT Jr, Gach HM, Boardman J, Bernick CB, Thompson PM, Becker JT: White matter lesions and brain gray matter volume in cognitively normal elders. Neurobiol Aging 2012;33:834.e7-834.e16.

17 Savva GM, Wharton SB, Ince PG, Forster G, Matthews FE, Brayne C, Medical Research Council Cognitive Function and Ageing Study: Age, neuropathology, and dementia. N Engl J Med 2009;360:2302-2309.

18 Launer LJ, Hughes TM, White LR: Microinfarcts, brain atrophy, and cognitive function: the Honolulu Asia Aging Study Autopsy Study. Ann Neurol 2011;70:774-780.

19 Chowdhury MH, Nagai A, Bokura H, Nakamura E, Kobayashi S, Yamaguchi S: Agerelated changes in white matter lesions, hippocampal atrophy, and cerebral microbleeds in healthy subjects without major cerebrovascular risk factors. J Stroke Cerebrovasc Dis 2011;20:302-309. 
20 Shim YS, Youn YC, Na DL, Kim SY, Cheong HK, Moon SY, Park KW, Ku BD, Lee JY, Jeong JH, Kang H, Kim EJ, Lee JS, Go SM, Kim SH, Cha KR, Seo SW: Effects of medial temporal atrophy and white matter hyperintensities on the cognitive functions in patients with Alzheimer's disease. Eur Neurol 2011; 66:75-82.

21 Chen W, Song X, Zhang Y, Darvesh S, Zhang N, D’Arcy RC, Black S, Rockwood K: An MRI-based semiquantitative index for the evaluation of brain atrophy and lesions in Alzheimer's disease, mild cognitive impairment and normal aging. Dement Geriatr Cogn Disord 2010;30:121-130.

-22 Zhang N, Song X, Zhang Y, Chen W, D'Arcy RC, Darvesh S, Fisk JD, Rockwood K, Alzheimer's disease Neuroimaging Initiative: An MRI brain atrophy and lesion index to assess the progression of structural changes in Alzheimer's disease, mild cognitive impairment, and normal aging: a follow-up study. J Alzheimers Dis 2011;26(suppl 3): 359-367.

-23 Weiner MW, Aisen PS, Jack CR Jr, Jagust WJ, Trojanowski JQ, Shaw L Saykin AJ, Morris JC, Cairns N, Beckett LA, Toga A, Green R, Walter S, Soares H, Snyder P, Siemers E, Potter W, Cole PE, Schmidt M, Alzheimer's Disease Neuroimaging Initiative: The Alzheimer's disease neuroimaging initiative: progress report and future plans. Alzheimers Dement 2010;6:201-211.e7.

-24 Jack CR Jr, Bernstein MA, Fox NC, Thompson P, Alexander G, Harvey D, Borowski B, Britson PJ, L Whitwell J, Ward C, Dale AM, Felmlee JP, Gunter JL, Hill DL, Killiany R, Schuff N, Fox-Bosetti S, Lin C, Studholme C, DeCarli CS, Krueger G, Ward HA, Metzger GJ, Scott KT, Mallozzi R, Blezek D, Levy J, Debbins JP, Fleisher AS, Albert M, Green R, Bartzokis G, Glover G, Mugler J, Weiner MW: The Alzheimer's Disease Neuroimaging Initiative (ADNI): MRI methods. J Magn Reson Imaging 2008;27:685-691.

25 Scheltens P, Leys D, Barkhof F, Huglo D, Weinstein HC, Vermersch P, Kuiper M, Steinling M, Wolters EC, Valk J: Atrophy of medial temporal lobes on MRI in 'probable' Alzheimer's disease and normal ageing: diagnostic value and neuropsychological correlates. J Neurol Neurosurg Psychiatry 1992; 55:967-972.

26 Barber R, Ballard C, McKeith IG, Gholkar A, O'Brien JT: MRI volumetric study of dementia with Lewy bodies: a comparison with $\mathrm{AD}$ and vascular dementia. Neurology 2008; 54:1304-1309.

-27 Burton EJ, Barber R, Mukaetova-Ladinska EB, Robson J, Perry RH, Jaros E, Kalaria RN, O’Brien JT: Medial temporal lobe atrophy on MRI differentiates Alzheimer's disease from dementia with Lewy bodies and vascular cognitive impairment: a prospective study with pathological verification of diagnosis. Brain 2009;132:195-203.
28 Visser PJ, Verhey FR, Hofman PA, Scheltens P, Jolles J: Medial temporal lobe atrophy predicts Alzheimer's disease in patients with minor cognitive impairment. J Neurol Neurosurg Psychiatry 2002;72:491-497.

29 Convit A, de Asis J, de Leon MJ, Tarshish CY, De Santi S, Rusinek H: Atrophy of the medial occipitotemporal, inferior, and middle temporal gyri in non-demented elderly predict decline to Alzheimer's disease. Neurobiol Aging 2000;21:19-26.

30 Killiany RJ, Hyman BT, Gomez-Isla T, Moss MB, Kikinis R, Jolesz F, Tanzi R, Jones K, Albert MS: MRI measures of entorhinal cortex vs hippocampus in preclinical $\mathrm{AD}$. Neurology 2002;58:1188-1196.

-31 Tondelli M, Wilcock GK, Nichelli P, De Jager CA, Jenkinson M, Zamboni G: Structural MRI changes detectable up to ten years before clinical Alzheimer's disease. Neurobiol Aging 2012;33:e25-e36.

- 32 Westman E, Cavallin L, Muehlboeck JS, Zhang Y, Mecocci P, Vellas B, Tsolaki M, Kłoszewska I, Soininen $\mathrm{H}$, Spenger C, Lovestone S, Simmons A, Wahlund LO, AddNeuroMed consortium. Sensitivity and specificity of medial temporal lobe visual ratings and multivariate regional MRI classification in Alzheimer's disease. PLoS One 2011;6:e22506.

33 Fox NC, Freeborough PA, Rossor MN: Visualisation and quantification of rates of atrophy in Alzheimer's disease. Lancet 1996;348: 94-97.

34 Shen Q, Loewenstein DA, Potter E, Zhao W, Appel J, Greig MT, Raj A, Acevedo A, Schofield E, Barker W, Wu Y, Potter H, Duara R: Volumetric and visual rating of magnetic resonance imaging scans in the diagnosis of amnestic mild cognitive impairment and Alzheimer's disease. Alzheimers Dement 2011; 7:e101-e108.

35 Waldemar G: Visual rating and ROI-based parametric analysis of rCBF SPECT in patients with mild or questionable dementia: a comparative study. Dement Geriatr Cogn Disord 2007;24:429-433.

36 DeCarli C, Frisoni GB, Clark CM, Harvey D, Grundman M, Petersen RC, Thal LJ, Jin S, Jack CR Jr, Scheltens P, Alzheimer's Disease Cooperative Study Group: Qualitative estimates of medial temporal atrophy as a predictor of progression from mild cognitive impairment to dementia. Arch Neurol 2007; 64:108-115.

37 Dickerson BC, Stoub TR, Shah RC, Sperling RA, Killiany RJ, Albert MS, Hyman BT, Blacker D, Detoledo-Morrell L: Alzheimer-signature MRI biomarker predicts $\mathrm{AD}$ dementia in cognitively normal adults. Neurology 2011;76:1395-1402.
38 van Straaten EC, Harvey D, Scheltens P, Barkhof F, Petersen RC, Thal LJ, Jack CR Jr, DeCarli C, Alzheimer's Disease Cooperative Study Group: Periventricular white matter hyperintensities increase the likelihood of progression from amnestic mild cognitive impairment to dementia. J Neurol 2008;255: 1302-1308.

39 Chen W, Song X, Zhang Y, for the Alzheimer's Disease Neuroimaging Initiative: Assessment of the Virchow-Robin spaces in Alzheimer's disease, mild cognitive impairment, and normal aging, using high-field MRI. AJNR Am J Neuroradiol 2011;32:1490-1495.

-40 Gold G, Kövari E, Herrmann FR, Canuto A, Hof PR, Michel JP, Bouras C, Giannakopoulos P: Cognitive consequences of thalamic, basal ganglia, and deep white matter lacunes in brain aging and dementia. Stroke 2005; 36:1184-1188.

-41 Carmichael O, Schwarz C, Drucker D, Fletcher E, Harvey D, Beckett L, Jack CR Jr, Weiner M, DeCarli C, Alzheimer's Disease Neuroimaging Initiative: Longitudinal changes in white matter disease and cognition in the first year of the Alzheimer disease neuroimaging initiative. Arch Neurol 2010; 67:1370-1378.

42 Schmidt R, Ropele S, Enzinger C, Petrovic K, Smith S, Schmidt H, Matthews PM, Fazekas F: White matter lesion progression, brain atrophy, and cognitive decline: the Austrian stroke prevention study. Ann Neurol 2005; 58:610-616.

43 Blum S, Luchsinger JA, Manly JJ, Schupf N, Stern Y, Brown TR, DeCarli C, Small SA, Mayeux R, Brickman AM: Memory after silent stroke: hippocampus and infarcts both matter. Neurology 2012;78:38-46.

44 Rossi R, Geroldi C, Bresciani L, Testa C, Binetti G, Zanetti O, Frisoni GB: Clinical and neuropsychological features associated with structural imaging patterns in patients with mild cognitive impairment. Dement Geriatr Cogn Disord 2007;23:175-183.

45 Appel J, Potter E, Bhatia N, Shen Q, Zhao W, Greig MT, Raj A, Barker WW, Potter H, Schofield E, Wu Y, Loewenstein DA, Duara $\mathrm{R}$ : Association of white matter hyperintensity measurements on brain MR imaging with cognitive status, medial temporal atrophy, and cardiovascular risk factors. AJNR Am J Neuroradiol 2009;30:1870-1876.

46 Jacobs HI, Van Boxtel MP, van der Elst W, Burgmans S, Smeets F, Gronenschild EH, Verhey FR, Uylings HB, Jolles J: Increasing the diagnostic accuracy of medial temporal lobe atrophy in Alzheimer's disease. J Alzheimers Dis 2011;25:477-490.

-47 Brickman AM, Honig LS, Scarmeas N, Tatarina O, Sanders L, Albert MS, Brandt J, Blacker D, Stern Y: Measuring cerebral atrophy and white matter hyperintensity burden to predict the rate of cognitive decline in Alzheimer disease. Arch Neurol 2008;65: 1202-1208. 
-48 de la Torre JC: Vascular risk factor detection and control may prevent Alzheimer's disease. Ageing Res Rev 2010;9:218-225.

49 Gouw AA, van der Flier WM, van Straaten EC, et al: Reliability and sensitivity of visual scales versus volumetry for evaluating white matter hyperintensity progression. Cerebrovasc Dis 2008;25:247-253.
50 Gao FQ, Swartz RH, Scheltens P, et al: Complexity of MRI white matter hyperintensity assessments in relation to cognition in aging and dementia from the Sunnybrook Dementia Study. J Alzheimers Dis 2011;26: 379-388.
51 Song X, Mitnitski A, Cox J, Rockwood K: Comparison of machine learning techniques with classical statistical models in predicting health outcomes. Stud Health Technol Inform 2004;107:736-740. 